\title{
Synthesis of MCM-41 nanoparticles from stem of common reed ash silica and their application as substrate in electrooxidation of methanol
}

\author{
SEYED NASER AZIZI ${ }^{1}$, SHAHRAM GHASEMI ${ }^{2, *}$ and OLIA RANGRIZ-ROSTAMI ${ }^{1}$ \\ ${ }^{1}$ Analytical Division, Faculty of Chemistry, University of Mazandaran, Babolsar 47416-95447, Iran \\ ${ }^{2}$ Faculty of Chemistry, University of Mazandaran, Babolsar 47416-95447, Iran \\ *Author for correspondence (sghasemimir@yahoo.com; sghasemi@umz.ac.ir)
}

MS received 11 May 2017; accepted 11 September 2017; published online 30 May 2018

\begin{abstract}
In this work, stem of common reed ash (SCRA) is introduced as a new source of silica in the preparation of mesoporous materials. Mesoporous silicate MCM-41 nanoparticles were synthesized hydrothermally using sodium silicate prepared from SCRA as a silica source. The characterization of MCM-41was carried out by X-ray diffraction (XRD), Fourier transform infrared spectroscopy (FTIR), scanning electron microscopy (SEM), $\mathrm{N}_{2}$ adsorption/desorption (BET) and transmission electron microscopy (TEM). SEM shows that MCM-41 nanoparticles are sphere-like with size in the range of 30-50 nm with some degree of agglomeration. TEM image of the synthesized sample shows the open framework structure of MCM-41. A type IV isotherm can be observed from adsorption/desorption curves, which is the characteristic of mesoporous materials. The prepared MCM-41 nanoparticles were used as substrate to facilitate the oxidation of methanol through the modification with an electroactive species. The modification was achieved by impregnation of MCM- 41 pores with $\mathrm{Ni}^{2+}$ ions (Ni-doped MCM-41). A modified carbon paste electrode (CPE) was prepared by mixing Ni-doped MCM-41 with carbon paste (NiMCM-41CPE). Cyclic voltammetry of NiMCM-41CPE shows an increment in current density of methanol oxidation in comparison with CPE in alkaline solution. Moreover, a decrease in the overpotential of methanol oxidation occurred on the surface of modified electrode. The effects of some parameters such as scan rate and methanol concentration are also investigated on the behaviour of NiMCM-41CPE. Also, the heterogeneous electron transfer rate for the catalytic reaction $(k)$ of methanol is calculated.
\end{abstract}

Keywords. MCM-41 nanoparticles; common reed silica ash; electrocatalysis; mesoporous materials; chronoamperometry.

\section{Introduction}

Because of increasing interest for environmentally clean and cheap energy sources, direct methanol fuel cells (DMFCs) are being considered as power sources. Methanol is a popular fuel in DMFC, which has advantages such as simplicity in the storage, operation and transportation in comparison with hydrogen-based fuel cells [1]. Some reported advantages of DMFC are low pollution for environment, high energy density, ready availability of methanol fuel, ease in distribution and low operation temperature [2].

One of the main drawbacks of DMFC is slow kinetics of the methanol oxidation reaction at the anode due to production of intermediate species and poisoning of the catalysts, which can lead to high overpotentials and limitation in the performance of DMFCs. Noble metals, binary or ternary alloys and their composite such as Pt-Ru [3], Pd-Fe [4], Pt-Sn [5], Au-Pt [6], Pt-Cu [7], Pt-polyaniline [8] and Ru-deposited NiZn [9] are some proposed electrocatalyst materials for the methanol oxidation.

Although Pt and Pt-based alloys are very effective in the anodic oxidation of methanol, but some parameters such as cost price, limited supply and deactivation due to surface poisoning by the reaction intermediates and products are some challenging items in the application of noble metals. While considering such problems, a great deal of interest is focussed on the preparation of non-noble metals for oxidation of methanol. Among them, nickel is a promising catalyst, which has low cost and good stability in alkaline solutions. Abdel Rahim et al [10] reported that Ni dispersed on graphite presents a good catalytic activity towards methanol oxidation, but massive $\mathrm{Ni}$ does not show suitable behaviour. $\mathrm{Xu}$ et al [11] fabricated Ni hollow spheres using silica spheres as template. These spheres were applied to methanol and ethanol electrooxidation in alkaline media. A very high current and activity towards methanol electrooxidation were observed on 
Ni hollow spheres in comparison with Ni particles. Also, more negative shifts in the onset and peak potentials for methanol oxidation were observed in the presence of Ni hollow spheres with respect to $\mathrm{Ni}$ particles.

On the other hand, Ni species were loaded in different modified electrodes and used as electrocatalyst for methanol oxidation. Phosphotungstic acid-nickel composite-modified carbon paste electrode was proposed as efficient electrocatalyst with low overpotential and high current density for methanol oxidation in alkaline solution [12]. Zeng and Song [13] proposed a Ni(II)-quercetin (Qu) complex modified multi-wall carbon nanotube paste electrode (Ni(II)$\mathrm{Qu}-\mathrm{MWCNT}-\mathrm{PE}$ ) for electrocatalytic oxidation of methanol. They showed that Ni(II)-Qu-MWCNT-PE exhibits improved reversibility and enhanced current responses of the $\mathrm{Ni}(\mathrm{III}) / \mathrm{Ni}$ (II) couple compared with $\mathrm{Ni}$ (II)-MWCNT-PE and $\mathrm{Ni}(\mathrm{II})-\mathrm{Qu}-\mathrm{carbon}$ paste electrode. Also, Golikand et al [14] used a nickel electrode modified by nickel-dimethylglyoxime (NiODMG) complex formed by electrochemical synthesis for electrocatalytic oxidation of methanol. The obtained results confirmed that the NiODMG film on the Ni electrode provides an efficient catalyst for the electrooxidation of methanol in alkaline medium via the formation of $\mathrm{Ni}$ (III) species on the electrode surface. Also, electropolymerized Ni(II)curcumin complex [15] and poly(Ni ${ }^{\mathrm{II}}$-tetramethyldibenzotetraaza [14] annulene) (NiII-(tmdbta)) on glassy carbon electrodes [16] are other complex-based materials used for methanol oxidation. Also, Ni-based alloys and Ni-dispersed on polymers are other examples of fabricated modified electrodes.

Jafarian et al [17] proposed a $\mathrm{Ni}-\mathrm{Cu}$ alloy modified electrode for catalytic oxidation of methanol in alkaline solution. Carbon-paste electrodes modified with nickelpoly(o-aminophenol) [18], nickel ions dispersed into poly(1,5-diaminonaphthalene) film [19] and nickel particles electrodeposited into poly(m-toluidine) film [20] as well as nickel ions dispersed onto poly(o-toluidine)/Triton X-100 film at the surface of MWCNT-paste electrode [21] are the electrodes proposed to facilitate the methanol oxidation.

Porous materials such as zeolites and ordered mesoporous silicate materials can provide several hundred holes and channels for encapsulation of transition metals and their complexes to prepare modified electrodes. Pt nanoparticles confined in SBA-15 [22] and Ni-ZSM-5 [23,24], Ni-SBA-15 [25] and Ni-SBA-16 [26] and Ni-P [27] zeolites mixed with carbonpaste electrodes were used for electrocatalytic oxidation of methanol.

Porous materials such as M41s and SBA families have promising features due to their larger pore sizes and surface area than zeolite. Since Mobile Corporation discovered the M41S family of mesoporous materials in 1992, they were used widely in different research areas such as catalysts or catalyst supports of metals [28]. MCM-41 as main member of the M41S family has excellent properties such as high surface area, high thermal stability and narrow pore-size distribution, which can be synthesized economically with inexpensive silica sources. It is applied in research areas such as catalyst support [29], environmental purification [30] and adsorbent [31].

Self-grown plants on the river beach such as common reed (Phragmites australis) is noticed as wastage and is not considered properly, but it can be used as an energy source in many industries. Stem of common reed ash (SCRA) is rich in silica and can be used as cheap silica sources for industrial scale production of mesoporous materials. The extracted silica of SCRA is found with high purity, low mineral impurity and in the form of amorphous (most reactive form for silylation reaction).

In this work, sol-gel technique was used to prepare mesoporous silica MCM-41 nanoparticles by using silica extracted from SCRA in the presence of co-templates hexadecyltrimethyl ammonium bromide (CTAB) as structuredirecting agent under hydrothermal conditions. Then, $\mathrm{Ni}^{2+}$ incorporated mesoporous silicate materials were prepared through impregnation procedure and used as modifier in the preparation of Ni-doped MCM-41 carbon-paste electrode (NiMCM-41CPE). Then, the efficiency of modified electrode was investigated for methanol electrooxidation reaction in alkaline medium by electrochemical techniques.

\section{Experimental}

\subsection{Apparatus and chemicals}

$\mathrm{SiO}_{2}$ powder was extracted from stem of common reed ash as silica source. CTAB, graphite powder, nickel chloride, methanol, paraffin, ammonium hydroxide and sodium hydroxide were purchased from Merck.

The chemical composition of the SCRA was analysed by X-ray fluorescence spectroscopy (XRF, $8410 \mathrm{Rh} 60 \mathrm{kV}$ ) and is shown in table 1. X-ray diffraction (XRD) pattern of the mesoporous silica was recorded on an X-ray diffractometer (SIEMENS D5000) using $\mathrm{CuK} \alpha$ radiation. The framework vibrations of mesoporous silica was recorded at room temperature using $\mathrm{KBr}$ pellet by Fourier transform infrared spectroscopy (FTIR, Vector 22-Bruker), in the range of 500$4000 \mathrm{~cm}^{-1}$. The surface morphology and structure of the calcined mesoporous silica was studied by field-emission scanning electron microscopy (FESEM, HITACHI, S-4160) and transmission electron microscopy (TEM, Philips CM120 instrument at an acceleration voltage of $100 \mathrm{kV}$ ). Specific surface area was determined by BET surface area analyzer (Coulter model BELSORP mini 100 instruments). The particle size distribution of the samples was determined

Table 1. Chemical compositions of SCRA (wt \%) characterized by XRF.

\begin{tabular}{llllllll}
\hline $\mathrm{SiO}_{2}$ & $\mathrm{P}_{2} \mathrm{O}_{5}$ & $\mathrm{~K}_{2} \mathrm{O}$ & $\mathrm{CaO}$ & $\mathrm{MgO}$ & $\mathrm{Fe}_{2} \mathrm{O}_{3}$ & $\mathrm{Na}_{2} \mathrm{O}$ & $\mathrm{Al}_{2} \mathrm{O}_{3}$ \\
\hline 84.020 & 7.482 & 2.613 & 1.918 & 1.435 & 1.361 & 0.309 & 0.183 \\
\hline
\end{tabular}


by nitrogen adsorption data using the conventional Barrett-Joyner-Halenda (BJH) method. The electrochemical experiments were conducted using a Dropsens, Bipotentiostat/Galvanostat ( $\mu$ STAT 400). A platinum wire, an $\mathrm{Ag}|\mathrm{AgCl}| \mathrm{KCl}$ (3 M) electrode (both from Azar electrode Co., Iran) and NiMCM-41CPE were used as auxiliary, reference and working electrodes, respectively.

\subsection{Preparation of pure silica powder from SCRA}

$\mathrm{SiO}_{2}$ powder was extracted from SCRA using Kalapathy et al's method [32]. Stem of common reed samples were collected from Mazandaran province in the north of Iran. At first, the samples were cleaned and washed with water to remove adhering soil and dust and then dried at $100^{\circ} \mathrm{C}$ overnight. Dried stem of common reed samples were completely burned in air. SCRA was steeped in $1 \mathrm{M} \mathrm{HCl}$ for $4 \mathrm{~h}$. After acid pretreatment, the mixture was filtered and washed with distilled water several times until the filtrate became acid-free. The acid-leached sample was then dried at $100^{\circ} \mathrm{C}$ overnight and calcined at $600^{\circ} \mathrm{C}$.

Sodium silicate was prepared from silica-contained ash powder with refluxing in sodium hydroxide solution under vigorous stirring at $100^{\circ} \mathrm{C}$ for $4 \mathrm{~h}$. The mixture was filtered and the obtained solution was cooled to room temperature and neutralized by $1 \mathrm{M} \mathrm{HCl}$ to form silica aqua gel. Then, it was washed by deionized water to remove soluble salts and dried at $80^{\circ} \mathrm{C}$ overnight to produce silica xerogel. It was transferred to a pounder to obtain pure silica powder.

\subsection{Synthesis of MCM-41 mesoporous nanoparticles}

To synthesize mesoporous MCM-41 by hydrothermal method, $1.36 \mathrm{~g}$ CTAB was dissolved in $47.43 \mathrm{ml}$ of deionized water and $0.1 \mathrm{ml}$ ethanol, and then $3.5 \mathrm{ml}$ ammonia solution was added to this solution. After $10 \mathrm{~min}$ stirring, alkaline sodium silicate solution was added drop-wise to this mixture and stirring was continued for $2.5 \mathrm{~h}$ at room temperature to obtain gel. Then, it was transferred into a Teflon autoclave and heated at $373 \mathrm{~K}$ for $24 \mathrm{~h}$. Finally, the white precipitate was filtered, washed and dried in oven and then calcined at $823 \mathrm{~K}$ in air for $6 \mathrm{~h}$ to remove the organic template.

\subsection{Electrode preparation}

Modified MCM-41 was prepared by exchanging ions of mesoporous silica (usually $\mathrm{Na}^{+}$) by nickel (II) ions. Three hundred milligrams of mesoporous silica was grinded and dispersed to $10 \mathrm{ml}$ of $0.1 \mathrm{M} \mathrm{NiCl}_{2}$ solution for $24 \mathrm{~h}$ to replace $\mathrm{Na}^{+}$ions in the MCM-41 by $\mathrm{Ni}^{2+}$. Then, the mixture was filtered and washed by deionized water to remove any surface-adsorbed $\mathrm{Ni}^{2+}$ and dried in an oven overnight.

Modified carbon paste with an optimized ratio of $30 \%$ (W/W) was made by hand-mixing of $0.3 \mathrm{~g}$ of NiMCM-41 with $0.7 \mathrm{~g}$ graphite powder in diethyl ether. After evaporation of solvent, paraffin was blended by hand mixing to obtain uniformly wetted carbon paste. The resulting paste was inserted in the bottom of a glass tube (with internal radius $1.5 \mathrm{~mm}) . \mathrm{Cu}$ wire was used as an electrical connection. The modified electrode (NiMCM-41CPE) was immersed in $0.1 \mathrm{M} \mathrm{NiCl}_{2}$ solution for $5 \mathrm{~min}$ before each experiment and then rinsed with deionized water to remove surface-adsorbed species.

To investigate the main role of mesoporous silica in oxidation of methanol, MCM-41CPE was constructed with addition of non-modified MCM-41 prepared in the absence of $\mathrm{Ni}^{2+}$ to CPE (MCM-41CPE). Also, blank experiments were carried out at the surface of CPE and NiCPE prepared in the same way, but in the absence of MCM-41 to investigate the effect of mesoporous material in the electrocatalytic behaviour of NiMCM-41CPE in oxidation of methanol. To prepare NiCPE, CPE was firstly immersed in $0.1 \mathrm{M} \mathrm{NiCl}_{2}$ solution for $3 \mathrm{~h}$ and then rinsed with distilled water. $\mathrm{Ni}$ species became stable at the surface of the modified electrodes by cycling the potential between 0 and $1 \mathrm{~V}$ for several times in $0.1 \mathrm{M} \mathrm{NaOH}$.

\section{Results and discussion}

\subsection{Characterization of $M C M-41$}

Table 1 shows chemical compositions of SCRA measured by XRF. From XRF, it is shown that SCRA consists of $84.02 \%$ $\mathrm{SiO}_{2}$ and small percent of other metal oxides such as $\mathrm{Al}_{2} \mathrm{O}_{3}$, $\mathrm{CaO}, \mathrm{Fe}_{2} \mathrm{O}_{3}, \mathrm{Na}_{2} \mathrm{O}, \mathrm{MgO}, \mathrm{K}_{2} \mathrm{O}$ and $\mathrm{P}_{2} \mathrm{O}_{5}$. This indicates that SCRA is a good silica source for direct synthesis of mesoporous silica (MCM-41).

Figure 1 shows the low-angle XRD pattern of calcined sample. The sharp and intense peak at $2 \theta \sim 2-3^{\circ}$ corresponding to reflection plane (100) confirms the formation of ordered hexagonal structure of MCM-41. Other weak peaks in figure 1 corresponding to the (110), (200) and (210) planes

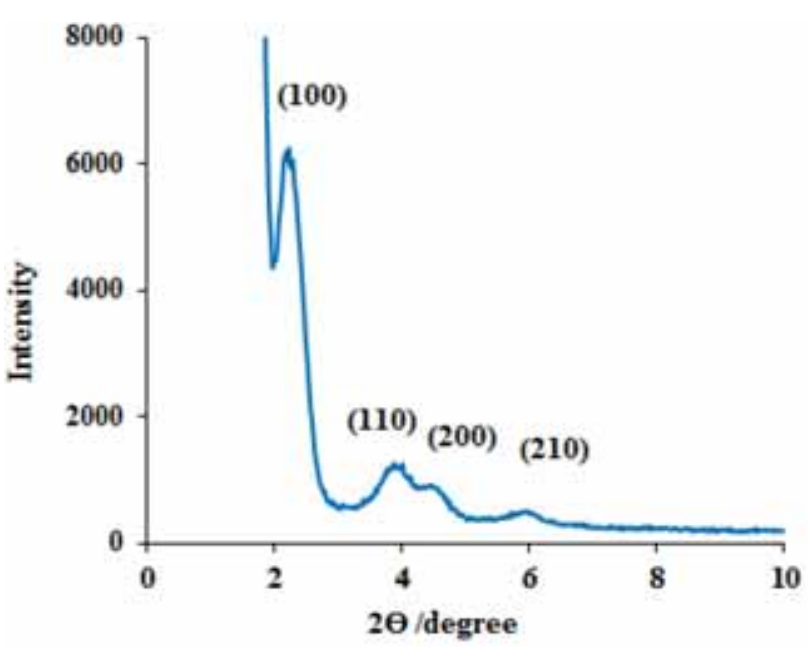

Figure 1. Small-angle XRD pattern of calcined mesoporous MCM-41 nanoparticles. 


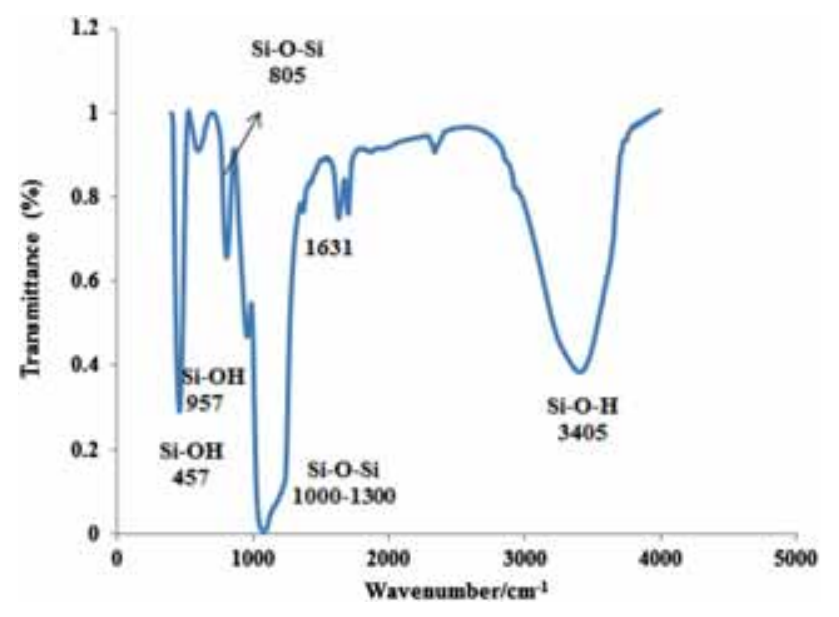

Figure 2. FTIR spectra of synthesized mesoporous MCM-41 nanoparticles.

show the formation of the highly ordered structure of MCM41 [28].

The FTIR of MCM-41 is presented in figure 2. A broad absorption band around $3400 \mathrm{~cm}^{-1}$ is assigned to the $\mathrm{O}-\mathrm{H}$ stretching vibration mode of the silanol groups and adsorbed water molecules, while deformational vibrations of adsorbed molecules cause the absorption bands at around $1631 \mathrm{~cm}^{-1}$. The sample also shows a peak at $805 \mathrm{~cm}^{-1}$ assigned to symmetric stretching mode of $\mathrm{Si}-\mathrm{O}-\mathrm{Si}$ bonds [33], while the peak at $957 \mathrm{~cm}^{-1}$ is appropriated to overlapped vibration modes of non-reacted $\mathrm{SiO}_{2}$ and $\mathrm{Si}-\mathrm{OH}$ symmetric stretching vibrations [34]. The broad absorbance band in $1000-1300 \mathrm{~cm}^{-1}$ region is referred to $\mathrm{Si}-\mathrm{O}-\mathrm{Si}$ anti-symmetric stretching [34]. The sample also shows a peak at $805 \mathrm{~cm}^{-1}$ assigned to symmetric stretching mode of $\mathrm{Si}-\mathrm{O}-\mathrm{Si}$ bonds [35]. The band at around $457 \mathrm{~cm}^{-1}$ is assigned to bending vibration of $\mathrm{Si}-\mathrm{OH}$ group.

The morphology and size of the MCM-41 nanoparticles are investigated by SEM (figure 3a). The calcined sample is composed of agglomerated sphere-shaped nanoparticles with the size in a range of $30-50 \mathrm{~nm}$. Figure $3 \mathrm{~b}$ and c shows TEM image of the synthesized sample at two different magnifications, which shows details of the open framework structure of MCM-41.

Adsorption/desorption of nitrogen is shown in figure 4A. A type IV isotherm is observed which is characteristic of a mesoporous material. Figure 4B displays the pore-sized distribution of MCM-41 based on BJH method. According to figure $4 b$, the synthesized MCM-41 has narrow pore-size distribution. The structural properties of the calcined sample are tabulated in table 2 .

\subsection{Electrochemical behaviour of NiMCM-41 CPE}

The cyclic voltammetry is used to investigate the behaviour of electrodes in alkaline solution. At CPE, in the absence and presence of 0.03 M methanol (supplementary figures S1 and $5 b$ ), no redox peak is observed in $0.1 \mathrm{M} \mathrm{NaOH}$ recorded at $25 \mathrm{mV} \mathrm{s}^{-1}$, which means a kinetically sluggish oxidation of methanol is occurred, while at NiMCM-41CPE (figure 5a), one pair of redox peaks appears. Such behaviour shows that on modified electrode and in the presence of electroactive $\mathrm{Ni}$ species, the methanol oxidation is catalysed through decreasing the overpotential of reaction. $\mathrm{Ni} / \mathrm{MCM}-41$ operates as catalyst in the oxidation of methanol in $0.1 \mathrm{M} \mathrm{NaOH}$.

According to Bessel and Rolison [36] proposed mechanism, ion exchange between the $\mathrm{Ni}^{2+}$ ions incorporated in mesoporous silica MCM-41 with $\mathrm{Na}^{+}$ions in the electrolytes occurs at the surface of electrode NiMCM-41CPE:

$$
\mathrm{Ni}_{(\mathrm{ms})}^{2+}+2 \mathrm{Na}_{(\mathrm{s})}^{+} \rightarrow \mathrm{Ni}_{(\text {int })}^{2+}+2 \mathrm{Na}_{(\mathrm{ms})}^{+}
$$

where descriptors $\mathrm{ms}$, $\mathrm{s}$ and int represent for mesoporous silica, solution and mesoporous silica-solution interface, respectively.

In alkaline solution, $\mathrm{Ni}^{2+}$ ions at the mesoporous silica/electrolyte interface combine with $\mathrm{OH}^{-}$and converted to $\mathrm{Ni}(\mathrm{OH})_{2}$ species according to the following equation:

$$
\mathrm{Ni}^{2+}+2 \mathrm{OH}^{-} \rightarrow \mathrm{Ni}(\mathrm{OH})_{2}
$$

Potential scanning of NiMCM-41CPE in $\mathrm{NaOH}$ was repeated several times to achieve a stable behaviour of modified electrode and at such condition, $\mathrm{Ni}^{2+}$ ions are trapped in pores of mesoporous MCM-41 through the formation of nickel hydroxide. With such process, Ni species remain on the surface of electrode and become stable. As can be seen in figure $5 \mathrm{a}$, one redox peak is observed at scan rate of $25 \mathrm{mV} \mathrm{s}^{-1}$ due to the oxidation of the $\mathrm{Ni}(\mathrm{OH})_{2}$ to the nickel oxy-hydroxide $(\mathrm{NiOOH})$ and the reduction of $\mathrm{NiOOH}$ to $\mathrm{Ni}(\mathrm{OH})_{2}[37,38]$ :

$$
\mathrm{Ni}(\mathrm{OH})_{2}+\mathrm{OH}^{-} \rightarrow \mathrm{NiOOH}+\mathrm{H}_{2} \mathrm{O}+e^{-} .
$$

A set of electrodes was designed to resolve the role of MCM-41 in oxidation of methanol. Cyclic voltammograms of NiCPE (figure 5c), MCM-41CPE (figure 6D) and NiMCM$41 \mathrm{CPE}$ (figure 5e) were recorded in the solution of $0.03 \mathrm{M}$ methanol in $0.1 \mathrm{M} \mathrm{NaOH}$. With the addition of methanol, considerable anodic current is observed on NiMCM-41CPE during the anodic scan at $0.77 \mathrm{~V}$ (figure 5e). Such prominent increment in anodic current is an evidence of facilitated electrochemical oxidation of methanol on the surface of modified electrode and relies on the presence of redox active species of $\mathrm{Ni}$ in the pores of mesoporous silica.

To optimize the amount of modifier, the response of the NiMCM-41CPE at different ratios $(20,30$ and 40\% (W/W)) of NiMCM-41 were examined by cyclic voltammetry in the presence of $0.1 \mathrm{M}$ methanol in $0.1 \mathrm{M} \mathrm{NaOH}$ solution. When $30 \%$ (W/W) of NiMCM-41 is mixed with graphite paste, the oxidation of methanol produce higher anodic current. At low wt\% of MCM-41, the available MCM-41 pores, which can be doped with $\mathrm{Ni}^{2+}$ is decreased and due to it, the number of reaction active sites $\left(\mathrm{Ni}(\mathrm{OH})_{2}\right)$ diminishes at the surface of modified electrode. MCM-41 is an insulating material 

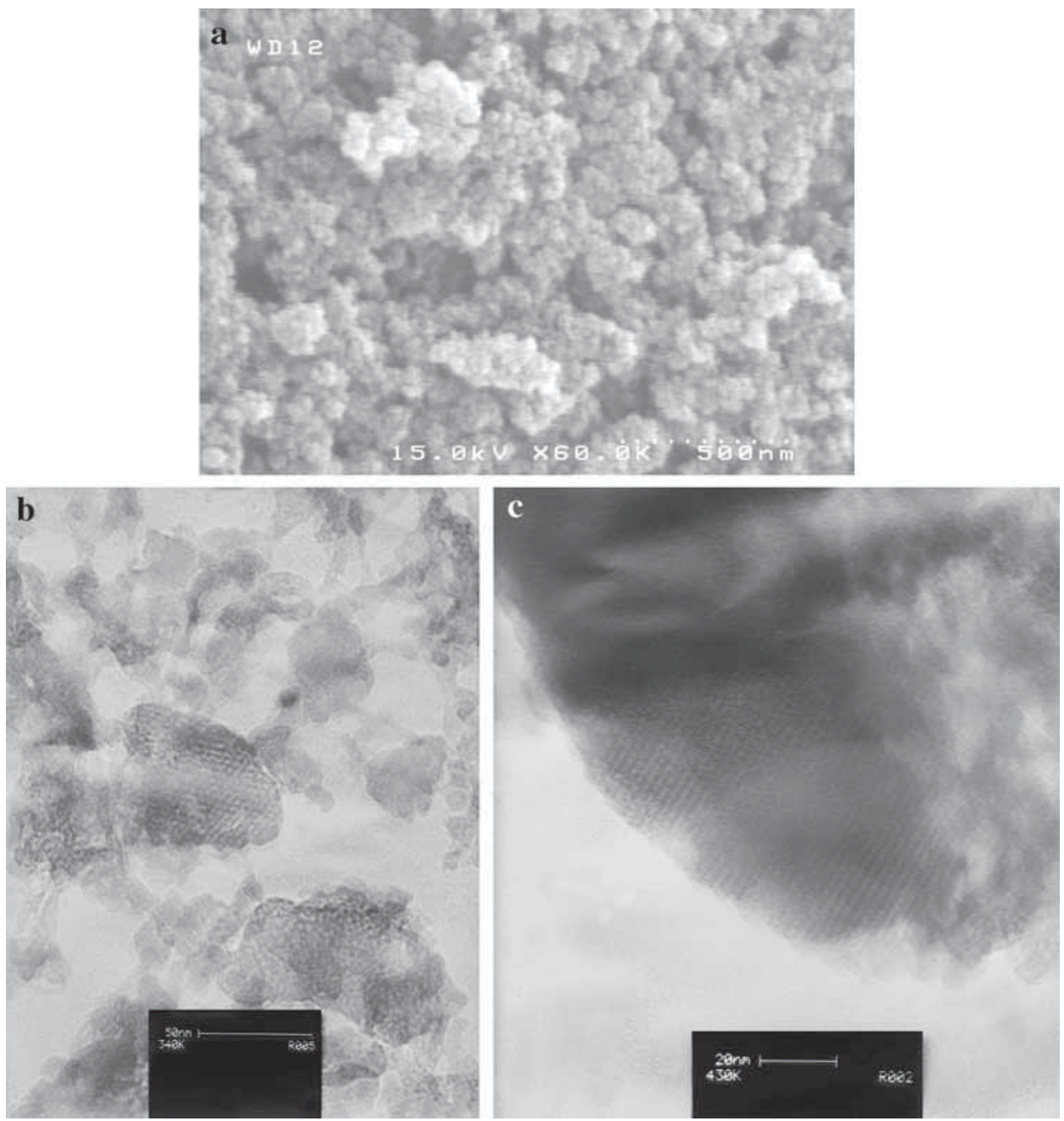

Figure 3. (a) SEM and (b and c) TEM images of synthesized mesoporous MCM-41 nanoparticles at two different magnifications.

so that an increase in the MCM-41 percent causes lower conductivity of prepared carbon paste and eventually, the current of methanol oxidation decreases.

Interesting results are obtained when CPE is modified with $\mathrm{Ni}^{2+}$. From figure $5 \mathrm{c}$, it is observed that the oxidation of methanol occurs at the surface of NiCPE as a small oxidation peak at $0.6 \mathrm{~V}$. Such evidence shows that the presence of $\mathrm{Ni}$ species in CPE are necessary for the oxidation process, but amount of adsorption of $\mathrm{Ni}^{2+}$ in $\mathrm{CPE}$ is lower than MCM-41CPE and from this, the essential role of MCM-41 can be described. During the potential cycling of NiMCM-41CPE in alkaline solution, the conversion of redox active species of $\mathrm{Ni}^{2+} / \mathrm{Ni}^{3+}$ to each other and not related to MCM-41 activity.

Even though an increase in current in the presence of methanol is observed at NiCPE, but it is noticeably lower when compared to NiMCM-41. With comparison among different electrodes, only NiMCM-41CPE shows an increase in anodic oxidation current that means the mesoporous silica
MCM-41 can collaborate in the oxidation of methanol. The capital role of MCM-41 appears in its mesoporous structure with large number of pores, where the diffusion of $\mathrm{Ni}^{2+}$ ions and their conversion to $\mathrm{NiOOH}$ species cause the acceleration of the oxidation of methanol process in comparison with NiCPE.

To delineate the electrochemical performance of modified electrode, the effect of scan rate is studied in $0.1 \mathrm{M}$ $\mathrm{NaOH}$. Figure 6A shows the cyclic voltammograms obtained at the surface of NiMCM-41CPE at different scan rates of potential in a wide range of $0.005-0.6 \mathrm{~V} \mathrm{~s}^{-1}$. Redox peaks with a half wavepotential of $425 \mathrm{mV}$ and $\Delta E_{\mathrm{p}}\left(E_{\mathrm{pa}}-E_{\mathrm{pc}}\right)$ of $\sim 180 \mathrm{mV}$ at the potential sweep rate of $10 \mathrm{mV} \mathrm{s}^{-1}$ reappeared at cyclic voltammogram. $\Delta E_{\mathrm{p}}$ increases with scan rate, which arises from limitation in the charge transfer kinetics during the chemical interactions between the electrolyte ions and surface film of NiMCM-41CPE. Laviron [39] proposed a theory for the linear potential sweep voltammetric 

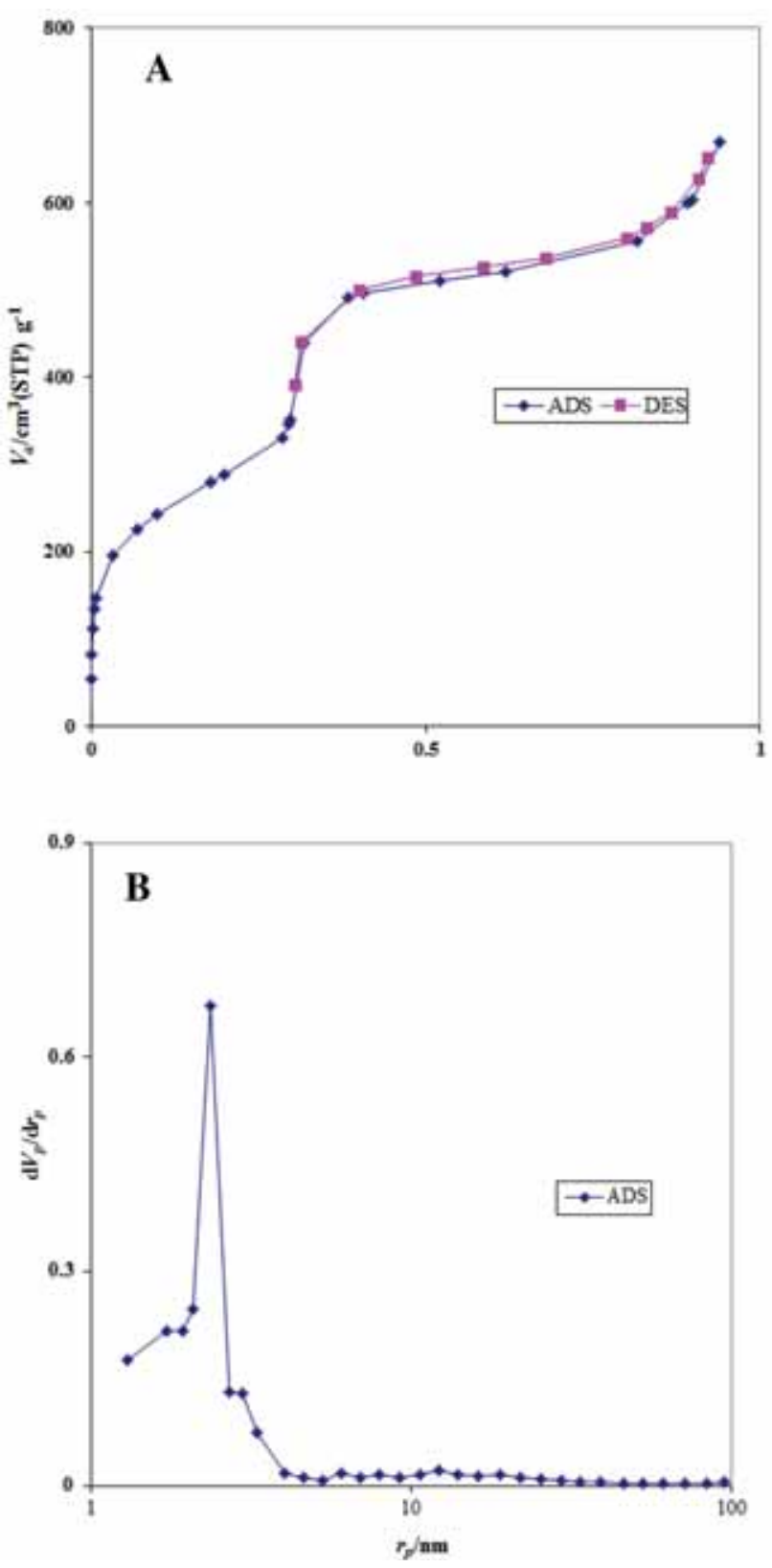

Figure 4. (A) Nitrogen adsorption-desorption isotherms and (B) pore-size distribution of mesoporous MCM-41 nanoparticles.

response of surface-confined electroactive species at small concentrations. In Laviron theory, for $\Delta E_{\mathrm{p}}>(0.2 / n) V$, where $n$ is the number of transferred electrons, the factors $\alpha$ and $k_{\mathrm{s}}$ (the transfer coefficient and the charge transfer rate constant, respectively) can be calculated as follows:

$$
\begin{aligned}
& E_{\mathrm{pa}}=E^{\circ}+X \ln \left[\frac{1-\alpha}{m}\right], \\
& E_{\mathrm{pc}}=E^{\circ}+Y \ln \left[\frac{\alpha}{m}\right],
\end{aligned}
$$

$$
\begin{aligned}
\log k_{\mathrm{s}}= & \alpha \log (1-\alpha)+(1-\alpha) \log \alpha-\log \left(\frac{R T}{n F v}\right) \\
& -\frac{\alpha(1-\alpha) n F \Delta E_{\mathrm{p}}}{2.303 R T} .
\end{aligned}
$$

where $X=R T /(1-\alpha) n F, Y=R T / \alpha n F, m=$ $(R T / F)\left(k_{\mathrm{s}} / n v\right)$. Also, $E_{\mathrm{pa}}$ and $E_{\mathrm{pc}}$ and $v$ are the anodic and cathodic peak potentials, scan rate, respectively. A plot of $E_{\mathrm{p}}$ with respect to $v$ can be used to calculate $\alpha$. Also, $k_{\mathrm{s}}$ is heterogeneous electron transfer rate constant of an electroactive compound (here $\mathrm{Ni}$ ) and can be computed with the aim of $\Delta E_{\mathrm{p}}$ at related scan rate and using calculated $\alpha$ [39].

A graph of anodic and cathodic peak potential $\left(E_{\mathrm{p}}\right) v s$. $\log v$ (figure 6B) is obtained from cyclic voltammograms of NiMCM-41CPE in $0.1 \mathrm{M} \mathrm{NaOH}$, which recorded at the range of $0.005-0.6 \mathrm{~V} \mathrm{~s}^{-1}$ (figure 6A). A linear dependence of $E_{\mathrm{p}}$ with $\log v$ is observed at $v>0.075 \mathrm{~V} \mathrm{~s}^{-1}$. From the slope of linear part of figure $6 \mathrm{~B}$ and applying equations (4) and (6), the value of anodic $(\alpha)$ and cathodic $(\beta)$ electron transfer coefficients are calculated to be 0.78 and 0.22 , respectively,which means that the different rate-limiting steps exist for the reduction and oxidation processes [40]. Also, $k_{\mathrm{s}}$ is equal to $0.046 \mathrm{~s}^{-1}$ at scan rate of $300 \mathrm{mV} \mathrm{s}^{-1}$.

As can be seen in figure $6 \mathrm{C}$, a linear dependence of both anodic and cathodic peak currents with scan rate are observed at low values from 0.005 to $0.075 \mathrm{~V} \mathrm{~s}^{-1}$ (figure 6C) ascribing to an electrochemical activity of deposited redox couple at the surface of modified electrode. Using equation (7), which is related to reversible process with adsorbed species, surface coverage can be calculated from the slope of linear section of figure 6C [41].

$$
I_{\mathrm{p}}=\frac{n^{2} F^{2} A v \Gamma^{*}}{4 R T}
$$

where $I_{\mathrm{p}}, A$ and $\Gamma^{*}$ are peak current, electrode surface area and surface coverage of the redox species $\left(\mathrm{Ni}(\mathrm{OH})_{2}\right)$, respectively. From equation (7), the average value of $\Gamma^{*}$ is obtained around $9.05 \times 10^{-8} \mathrm{~mol} \mathrm{~cm}^{-2}$ from cyclic voltammogram of electrode in $0.1 \mathrm{M} \mathrm{NaOH}$ and can be used to estimate the amount of Ni involved in redox process of NiMCM-41CPE. Both anodic and cathodic peak currents depend on square root of scan rate $\left(v^{1 / 2}\right)$ in scan rates of $v>0.075 \mathrm{~V} \mathrm{~s}^{-1}$ (figure 6D) due to domination of diffusion controlled process in the total redox behaviour of NiMCM-41CPE. The charge neutralization of the film during the oxidation/reduction process is the origin of such diffusion controlled process $[42,43]$. It seems probably that at low scan rate, the kinetic limitation of $\mathrm{Ni}(\mathrm{OH})_{2} / \mathrm{NiOOH}$ formed at the electrode surface for charge transfer controls the behaviour of electrode, while at high scan rate, the diffusion of $\mathrm{OH}^{-}$from bulk of solution to the electrode surface can control the total electrochemical behaviour of electrode, which appears as dependence of current to square root of scan rate. 
Table 2. Structural properties of mesoporous MCM-41 nanoparticles powder determined by nitrogen adsorption.

\begin{tabular}{lcccccc}
\hline Sample & $a_{\mathrm{S}}\left(\mathrm{m}^{2} \mathrm{~g}^{-1}\right)$ & $V_{\mathrm{t}}\left(\mathrm{cm}^{3} \mathrm{~g}^{-1}\right)$ & $\bar{r}_{\mathrm{p}}(\mathrm{nm})$ & $D_{\mathrm{BET}}(\mathrm{nm})$ & $V_{\mathrm{m}}\left(\mathrm{cm}^{3} \mathrm{~g}^{-1}\right)$ & $V_{\mathrm{p}}\left(\mathrm{cm}^{3} \mathrm{~g}^{-1}\right)$ \\
\hline MCM-41 & 814.7 & 0.8495 & 2.37 & 3.2764 & 74.248 & 0.7981 \\
\hline
\end{tabular}

Abbreviations: $a_{\mathrm{S}}$, the BET surface area; $V_{\mathrm{t}}$, total pore volume; $\bar{r}_{\mathrm{p}}$, average pore radius; $D_{\mathrm{BET}}$, average pore diameter; $V_{\mathrm{m}}$, micropore volume; $V_{\mathrm{p}}$, primary mesopore volume.

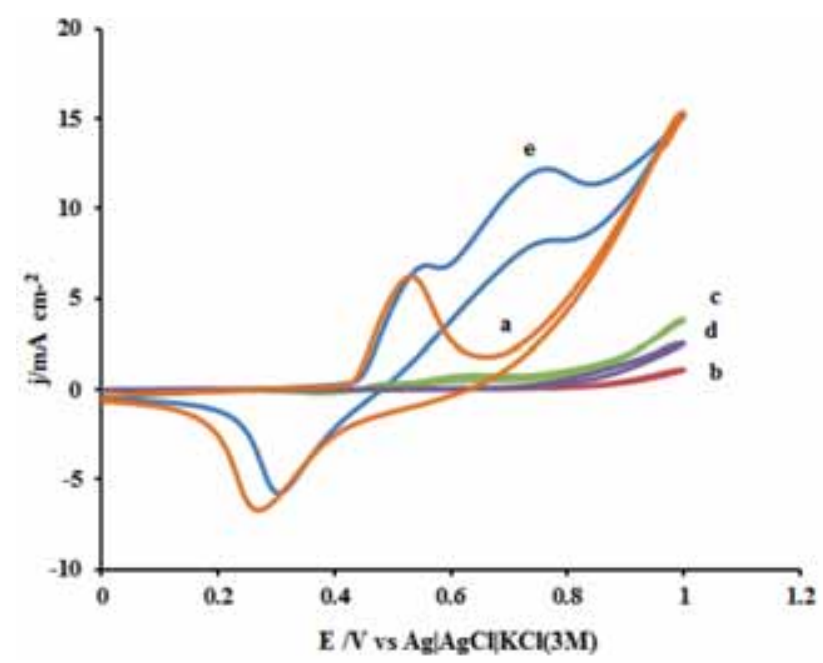

Figure 5. (a) Cyclic voltammograms of NiMCM-41CPE in the absence of methanol in $0.1 \mathrm{M} \mathrm{NaOH}$. Cyclic voltammograms of (b) CPE, (c) NiCPE, (d) MCM-41CPE and (e) NiMCM-41CPE in the presence of $0.03 \mathrm{M}$ methanol in $0.1 \mathrm{M} \mathrm{NaOH}$ at scan rate of $25 \mathrm{mV} \mathrm{s}^{-1}$.

\subsection{Redox behaviour of NiMCM-41CPE in methanol}

To delineate the mechanism of electrochemical oxidation of methanol on the modified electrode, the influence of methanol concentrations on the cyclic voltammetry responses of NiMCM-41CPE electrode was investigated (figure 7A). From figure 7B, in low concentration of methanol, there are two anodic peaks $\left(\mathrm{p}_{1}\right.$ and $\left.\mathrm{p}_{2}\right)$; one peak $\mathrm{p}_{1}$ at $\sim 0.57 \mathrm{~V}$ (assigned to the redox couple of $\alpha-\mathrm{Ni}(\mathrm{OH})_{2} / \mathrm{NiOOH}$ ) and another peak $\mathrm{p}_{2}$ at $0.77 \mathrm{~V}$ (assigned to the redox couple of $\left.\beta-\mathrm{Ni}(\mathrm{OH})_{2} / \mathrm{NiOOH}\right)$ can be observed [44-46].

$\mathrm{Ni}(\mathrm{OH})_{2}$ has two crystallographic forms, $\alpha-\mathrm{Ni}(\mathrm{OH})_{2}$ and $\beta-\mathrm{Ni}(\mathrm{OH})_{2} \cdot \alpha-\mathrm{Ni}(\mathrm{OH})_{2}$ is unstable form and is converted to $\mathrm{NiOOH}$ at lower potential, while $\beta-\mathrm{Ni}(\mathrm{OH})_{2}$ is a crystalline form with more resistance to oxidation and subsequently, it is appeared in higher potential. It was investigated by some authors that during the electrochemical oxidation of $\mathrm{Ni}$ electrode in alkaline solution, $\alpha$-form is formed at the initial stage of electrooxidation process although converted slowly to the $\beta-\mathrm{Ni}(\mathrm{OH})_{2}$ with further cycling [45]. According to previously observed evidence, it seems that $\alpha-\mathrm{Ni}(\mathrm{OH})_{2}$ is oxidized to $\mathrm{NiOOH}$ at peak potential of $\mathrm{p}_{1}$, but the presence of methanol reduces it and $\beta-\mathrm{Ni}(\mathrm{OH})_{2}$ is reformed. As a result, the anodic peak $\left(\mathrm{p}_{2}\right)$ appeared due to oxidation of $\beta-\mathrm{Ni}(\mathrm{OH})_{2}$ to $\mathrm{NiOOH}$ [47-49].

When the concentration of methanol increases, peak $\mathrm{p}_{2}$ grows noticeably and current of anodic peak $\mathrm{p}_{1}$ does not show significant increment. At high methanol concentration, more $\mathrm{NiOOH}$ species are converted to $\beta-\mathrm{Ni}(\mathrm{OH})_{2}$ through the methanol oxidation and more $\beta-\mathrm{Ni}(\mathrm{OH})_{2}$ species are available in oxidation process according to equation (8) [45]:

$$
\begin{aligned}
& \beta-\mathrm{Ni}(\mathrm{OH})_{2}+\mathrm{OH}^{-} \rightarrow \mathrm{NiOOH}+\mathrm{H}_{2} \mathrm{O}+e^{-}, \\
& \mathrm{NiOOH}+\mathrm{CH}_{3} \mathrm{OH} \rightarrow P_{\mathrm{ox}}+\mathrm{Ni}(\mathrm{OH})_{2},
\end{aligned}
$$

where $P_{\text {ox }}$ defines the eventual products of methanol oxidation such as carbonate, formaldehyde and formate anion $[21,50]$. The equations (8) and (9) show an $E C^{\prime}$ mechanism which can be described according to the following reactions:

$$
\begin{aligned}
& \mathrm{R} \leftrightarrow \mathrm{O}+n e^{-}, \\
& \mathrm{O}+\mathrm{X} \rightarrow \mathrm{R}+\mathrm{Y} .
\end{aligned}
$$

In this mechanism, $\mathrm{R}, \mathrm{O}, \mathrm{X}$ and $\mathrm{Y}$ are $\mathrm{Ni}(\mathrm{OH})_{2}, \mathrm{NiOOH}$, methanol and products of reaction, respectively. When potential is increased, $\mathrm{Ni}(\mathrm{OH})_{2}$ species $(\mathrm{R})$ are oxidized to $\mathrm{NiOOH}$ species $(\mathrm{O})$. Also, they can be reproduced during the reduction of NiOOH species by methanol (X). The net results of these two processes are increasing in the concentrations of $\mathrm{R}$ (which appears as increasing in the oxidation current of $\mathrm{Ni}(\mathrm{OH})_{2}$ oxidation (peak 2)) as well as decreasing in the concentrations of $\mathrm{NiOOH}$ species (diminish in the cathodic peak). As it can be seen, methanol can participate in reduction of $\mathrm{NiOOH}(\mathrm{O}$ species) to $\mathrm{Ni}(\mathrm{OH})_{2}$ (R species). It is expected that the oxidation and reduction peaks are only for $\mathrm{Ni}$ species. It means that the oxidation of methanol (X) did not appear as independent peak.

According to Fleischmann et al [37] mechanism, formaldehyde is produced as an active intermediate during the methanol oxidation and format ions can be the final products of methanol oxidation:

$$
\begin{aligned}
& \mathrm{Ni}(\mathrm{OH})_{2}+\mathrm{OH}^{-} \rightarrow \mathrm{NiOOH}+\mathrm{H}_{2} \mathrm{O}+e^{-}, \\
& \mathrm{NiOOH}+\mathrm{RCH}_{2} \mathrm{OH} \rightarrow \mathrm{Ni}(\mathrm{OH})_{2}+\mathrm{RC}^{\bullet} \mathrm{HOH}, \\
& \mathrm{RC} \bullet \mathrm{HOH}+3 \mathrm{OH}^{-} \rightarrow \mathrm{RCOOH}+2 \mathrm{H}_{2} \mathrm{O}+3 e^{-} .
\end{aligned}
$$



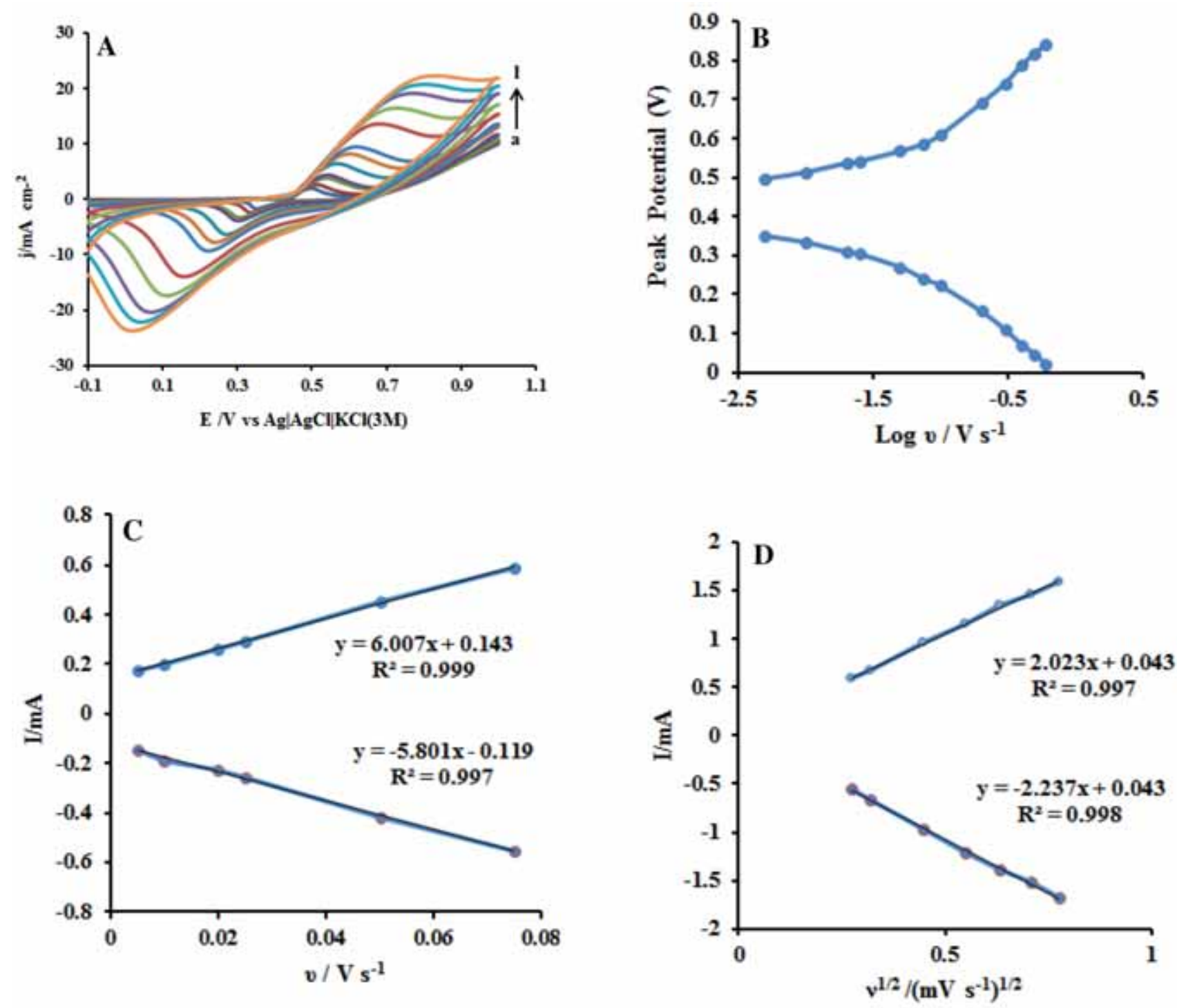

Figure 6. (A) Cyclic voltammograms recorded on the NiMCM-41CPE in $0.1 \mathrm{M} \mathrm{NaOH}$ at various scan rates: (a) 0.005 , (b) 0.010 , (c) 0.020 , (d) 0.025 , (e) 0.05 , (f) 0.075 , (g) 0.1, (h) 0.2, (i) 0.3, (j) 0.4, (k) 0.5 and (l) $0.6 \mathrm{~V} \mathrm{~s}^{-1}$. (B) Plot of $E_{\mathrm{p}} v s$. log $v$ for cyclic voltammograms of anodic and cathodic peaks. The dependency of $I_{\mathrm{pa}}$ and $I_{\mathrm{pc}}(\mathbf{C})$ on lower values of $v(0.005-0.075 \mathrm{~V} \mathrm{~s}-1)$ and $(\mathbf{D})$ on $v^{1 / 2}$ at higher values of $v\left(v>0.075 \mathrm{~V} \mathrm{~s}^{-1}\right)$.

In convenience with increasing the intensity of peak $\mathrm{p}_{2}$, a decrease in the current density of cathodic peak (assigned to $\mathrm{NiOOH}$ reduction) is observed at higher concentration of methanol during the reverse sweep. Although increase of anodic currents is due to conversion of more $\mathrm{NiOOH}$ to $\beta-\mathrm{Ni}(\mathrm{OH})_{2}$ through the methanol oxidation, but the intensity of cathodic peak current decreases because of the conversion of $\mathrm{NiOOH}$ to $\alpha-\mathrm{Ni}(\mathrm{OH})_{2}$. Mass normalized voltammograms of oxidation of $0.03 \mathrm{M}$ methanol at NiMCM-41CPE (i.e., current normalized per $\mathrm{Ni}$ load/ $\mathrm{Ag}^{-1} \mathrm{Ni}$ ) is given in figure $7 \mathrm{C}$ for comparison. On the electrode surface with surface area of $0.07065 \mathrm{~cm}^{2}$ (1.5 mm radius) and surface coverage of $9.05 \times 10^{-8} \mathrm{~mol} \mathrm{~cm}^{-2}$, the mole of Ni $\left(M_{\mathrm{w}}=58.69 \mathrm{~g} \mathrm{~mol}^{-1}\right)$ is calculated to be $6.39 \times 10^{-9} \mathrm{~mol}$. From this, the mass of $\mathrm{Ni}$ is obtained $3.75 \times 10^{-7} \mathrm{~g}$. Normalized current is calculated from dividing current in microampere with the mass of $\mathrm{Ni}$.

The effect of scan rate on kinetic of redox process occurred on NiMCM-41CPE was studied by cyclic voltammogram of $0.03 \mathrm{M}$ methanol in $0.1 \mathrm{M} \mathrm{NaOH}$ at different scans rates (figure 8). At low scan rates, two anodic peaks $\left(\mathrm{p}_{1}\right.$ and $\left.\mathrm{p}_{2}\right)$ appeared, which increases with the scan rate increment (figure $8 \mathrm{~b}$ ), whereas peak $\mathrm{p}_{2}$ strongly depends on the potential scan rate and even disappears in higher scan rates $\left(v>0.2 \mathrm{~V} \mathrm{~s}^{-1}\right)$.

At high scan rates, the conversion of $\beta-\mathrm{Ni}(\mathrm{OH})_{2}$ to $\mathrm{NiOOH}$ is not fast enough due to a kinetic limitation taking place in electron transfer with surface electrode. Since oxidation reaction of $\mathrm{Ni}(\mathrm{OH})_{2}$ to $\mathrm{NiOOH}$ has a fast electron transfer kinetic, the anodic peak current intensity $\left(\mathrm{p}_{1}\right)$ increases. This means 

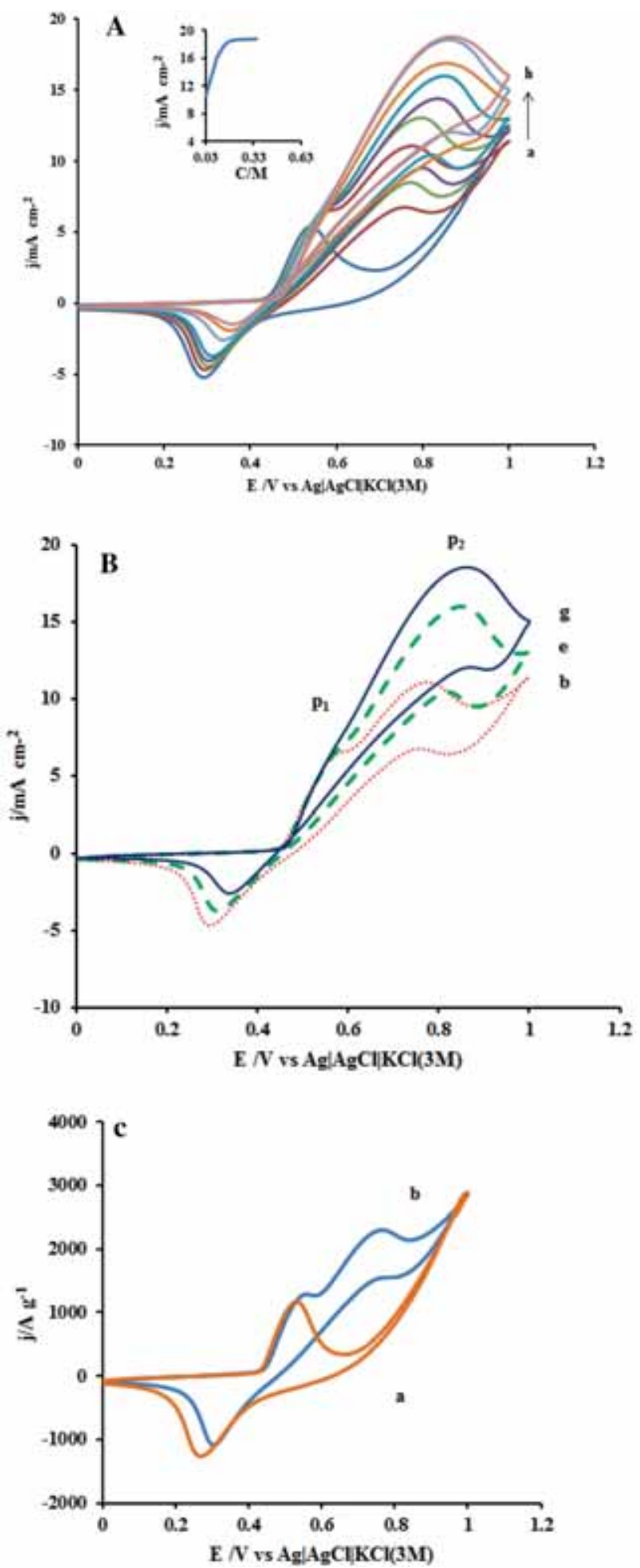

Figure 7. (A) Current-potential curves of the NiMCM-41CPE for electrocatalytic oxidation of methanol at the scan rate of $25 \mathrm{mV} \mathrm{s}^{-1}$ in $0.1 \mathrm{M} \mathrm{NaOH}$ solution with different concentrations of methanol: (a) 0.0, (b) 0.03, (c) 0.06, (d) 0.08, (e) 0.1, (f) 0.15, (g) 0.2 and (h) $0.35 \mathrm{M}$, respectively. (B) Zoomed cyclic voltammograms of (b), (e) and $(\mathrm{g})$ from the main panel of $(\mathbf{A})$. (C) A plot of mass activity of NiMCM-41CPE in the (a) absence and (b) presence of $0.03 \mathrm{M}$ of methanol.
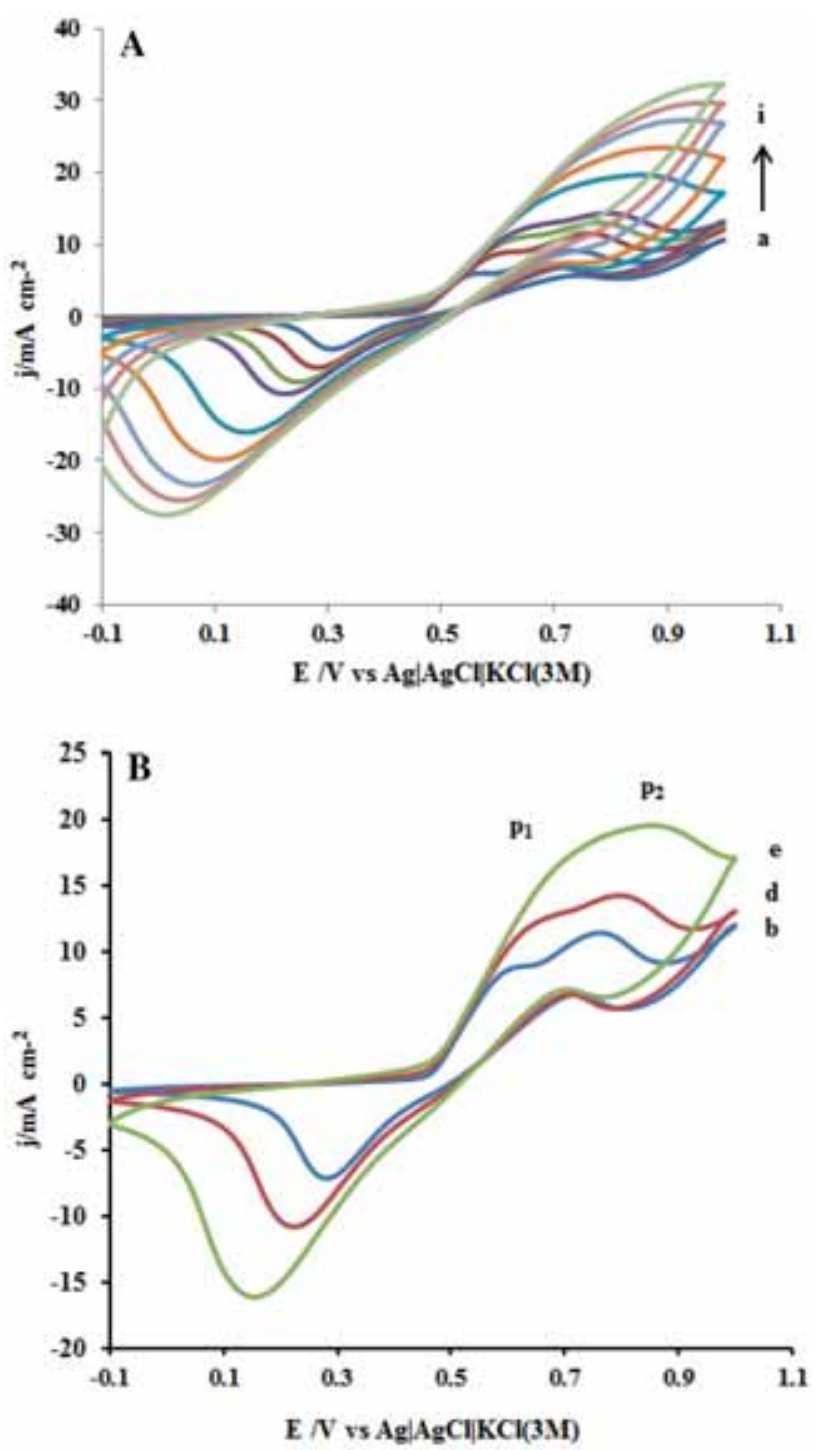

Figure 8. (A) Cyclic voltammograms of the NiMCM-41CPE in the presence of $0.03 \mathrm{M}$ methanol in $0.1 \mathrm{M} \mathrm{NaOH}$, scan rates: (a) 25, (b) 50, (c) 75, (d) 100, (e) 200, (f) 300, (g) 400, (h) 500 and (i) $600 \mathrm{mV} \mathrm{s}^{-1}$, respectively. (B) Zoomed cyclic voltammograms of (e), (d) and (b) from the main panel of (A).

that the anodic current principally arises from the oxidation of $\alpha-\mathrm{Ni}(\mathrm{OH})_{2}$ to $\mathrm{NiOOH}$.

The plot of the anodic peak current $\left(I_{\mathrm{pa}}\right) v s$. scan rate (figure $9 \mathrm{~b})$ obtained from cyclic voltammetry of NiMCM-41CPE in $0.03 \mathrm{M}$ methanol (figure 9a) gives further information about the process involved in redox behaviour of NiMCM-41CPE. Figure $9 \mathrm{~b}$ shows that the anodic peak current increases linearly with the square root of the sweep rate in the range of 5$600 \mathrm{mV} \mathrm{s}^{-1}$, that expresses the process is diffusion-controlled reaction rather than surface-controlled process.

Theoretically, the slope of the $\log I_{\mathrm{pa}}-\log v$ plots is expected to be 1.0 or 0.5 for adsorption or diffusion-controlled process, respectively [37]. Figure 9c shows a linear 

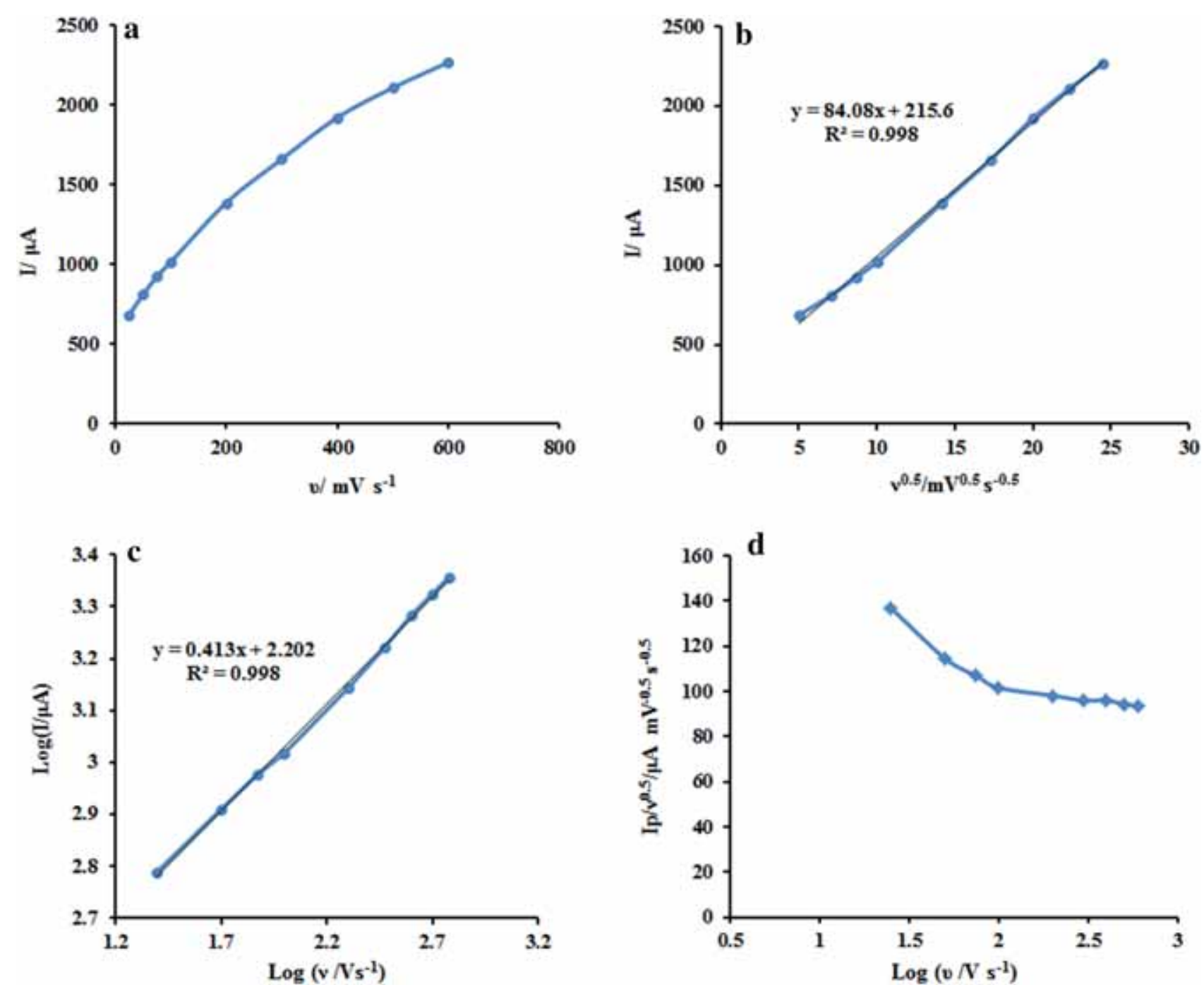

Figure 9. Plots of (a) $I_{\mathrm{pa}} v s . v$, (b) $I_{\mathrm{pa}} v s . v^{0.5}$, (c) $\log I_{\mathrm{pa}} v s . \log v$ and (d) $I_{\mathrm{pa}} / v^{0.5} v s . \log v$ for oxidation of $0.03 \mathrm{M}$ methanol in $0.1 \mathrm{M} \mathrm{NaOH}$ at NiMCM-41CPE.

dependence between $\log I_{\mathrm{pa}}$ and $\log v$ for methanol oxidation at NiMCM-41CPE with a slope value of 0.41 , which is near to theoretical expected value for a purely diffusion-controlled current. However, some difference with theoretical value is probably due to the contribution of a kinetic limitation to the overall process [51].

Figure 9d indicates the plot of scan rate normalized current $\left(I_{\mathrm{pa}} / v^{1 / 2}\right) v s$. logarithm scan rates. The observed behaviour is an evidence of an $\mathrm{EC}^{\prime}$ process that expresses the electrode reaction, which is coupled with an irreversible follow-up chemical step [52].

One of the main parameters in efficiency of NiMCM$41 \mathrm{CPE}$ is its mechanical and chemical stability in alkaline solution. To examine it, NiMCM-41CPE was cycled between 0 and $1 \mathrm{~V}$ in $0.1 \mathrm{M} \mathrm{NaOH}$ (at $25 \mathrm{mV} \mathrm{s}^{-1}$ ) and it was found that under repeated cycles, considerable change occurred in redox peaks of modified electrode, probably due to strong binding of $\mathrm{Ni}^{2+}$ ions to pores of mesoporous MCM-41 and a only few percent of $\mathrm{Ni}^{2+}$ could diffuse to solution in long time application of modified electrode. Also, the redox behaviour of NiMCM-41CPE was investigated in the presence of 0.03 $\mathrm{M}$ methanol and it was observed that only a slight change in current density of methanol oxidation was occurred in $0.1 \mathrm{M} \mathrm{NaOH}$ after several weeks. The sources of any changes are permeation of $\mathrm{Ni}^{2+}$ into solution or adsorption of product of methanol oxidation to $\mathrm{NiOOH}$ active sites. Also, the redox behaviour of NiMCM-41CPE in various concentrations of methanol showed a minor decrease in current density of anodic oxidation current and the response of the electrode can be easily repaired to its primary state by immersion of modified electrode in $0.1 \mathrm{M} \mathrm{NiCl}_{2}$ for $5 \mathrm{~min}$. Also, to obtain reliable and repeatable results, all modified electrodes were prepared daily. Also, to regenerate the primary behaviour of electrode, a thin layer of carbon paste was simply removed from the 
surface of modified electrode with polishing on paper. To investigate the reproducibility of NiMCM-41CPE, the redox behaviours of four different electrodes prepared at the same condition were investigated by cyclic voltammetry in the presence of methanol and the relative standard deviation of $2.9 \%$ was obtained, which means that the modified electrode provide good reproducibility.

\subsection{Chronoamperometric study}

The chronoamperometry was employed to determine the catalytic rate constant of the methanol oxidation on the NiMCM-41CPE. Figure 10 shows a double-step chronoamperograms ( $I-t$ curves) of redox process at NiMCM-41CPE. Current-time profiles are obtained by setting the working electrode potential at $700 \mathrm{mV}$ (in first step) and $350 \mathrm{mV}$ (in second step) vs. $\mathrm{Ag} \mid \mathrm{AgCl}(3 \mathrm{M} \mathrm{KCl})$. An exponential behaviour of $I-t$ amperograms (figure 10a) shows that a diffusion-controlled process take place, which can be modelled by a Cottrell equation [41]. A curve of $I v s . t^{-1 / 2}$ presents a linear relationship in the absence of methanol (figure 10a). From equation (15), the catalytic rate constant between the active sites of NiMCM-41CPE-modified electrode and methanol molecules can be estimated [53]:

$$
\frac{I_{\mathrm{c}}}{I_{\mathrm{L}}}=\gamma^{1 / 2}\left[\pi^{1 / 2} \operatorname{erf}\left(\gamma^{1 / 2}\right)+\exp (-\gamma) \gamma^{1 / 2}\right],
$$

where $I_{\mathrm{c}}$ and $I_{\mathrm{L}}$ are the catalytic and limiting currents of NiMCM-41CPE in the presence and absence of methanol, respectively. Also, $\gamma$ is the argument of error function and is shown as $\gamma=k C_{0} t\left(C_{0}\right.$ in the argument is attributed to the concentration of methanol in bulk solution). When $\gamma$ exceeds 2 , the error function is almost equal to 1 and equation (15) can be summarized as:

$$
\frac{I_{\mathrm{c}}}{I_{\mathrm{L}}}=\gamma^{1 / 2} \pi^{1 / 2}=\pi^{1 / 2}\left(k C_{0} t\right)^{1 / 2} .
$$

Parameters $k, C_{0}$ and $t$ describe the catalytic rate constant $\left(\mathrm{cm}^{3} \mathrm{~mol}^{-1} \mathrm{~s}^{-1}\right)$, methanol bulk concentration $\left(\mathrm{mol} \mathrm{l}^{-1}\right)$ and time (s), respectively. The value of catalytic rate constant is calculated from the slope of linear part of $I_{\mathrm{C}} / I_{\mathrm{L}}$ $v s$. $t^{1 / 2}$. According to figure $10 \mathrm{~b}$, the mean value of $k$ is found to be about $1.512 \times 10^{4} \mathrm{~cm}^{3} \mathrm{~mol}^{-1} \mathrm{~s}^{-1}$ from chronoamprogram of NiMCM-41CPE in the absence and presence of $0.1 \mathrm{M}$ methanol and shows that NiMCM-41CPE can present a good catalytic activity towards the methanol oxidation.

Table 3 compares the results obtained on the surface of NiMCM-41CPE with some previously reported electrodes for methanol electrooxidation. NiMCM-41CPE used in this work acts as an efficient electrocatalyst in the process of methanol oxidation when compared to other works. Also, it is necessary to note that to calculate the current density of the methanol oxidation alone, the current density of NiMCM-41CPE in
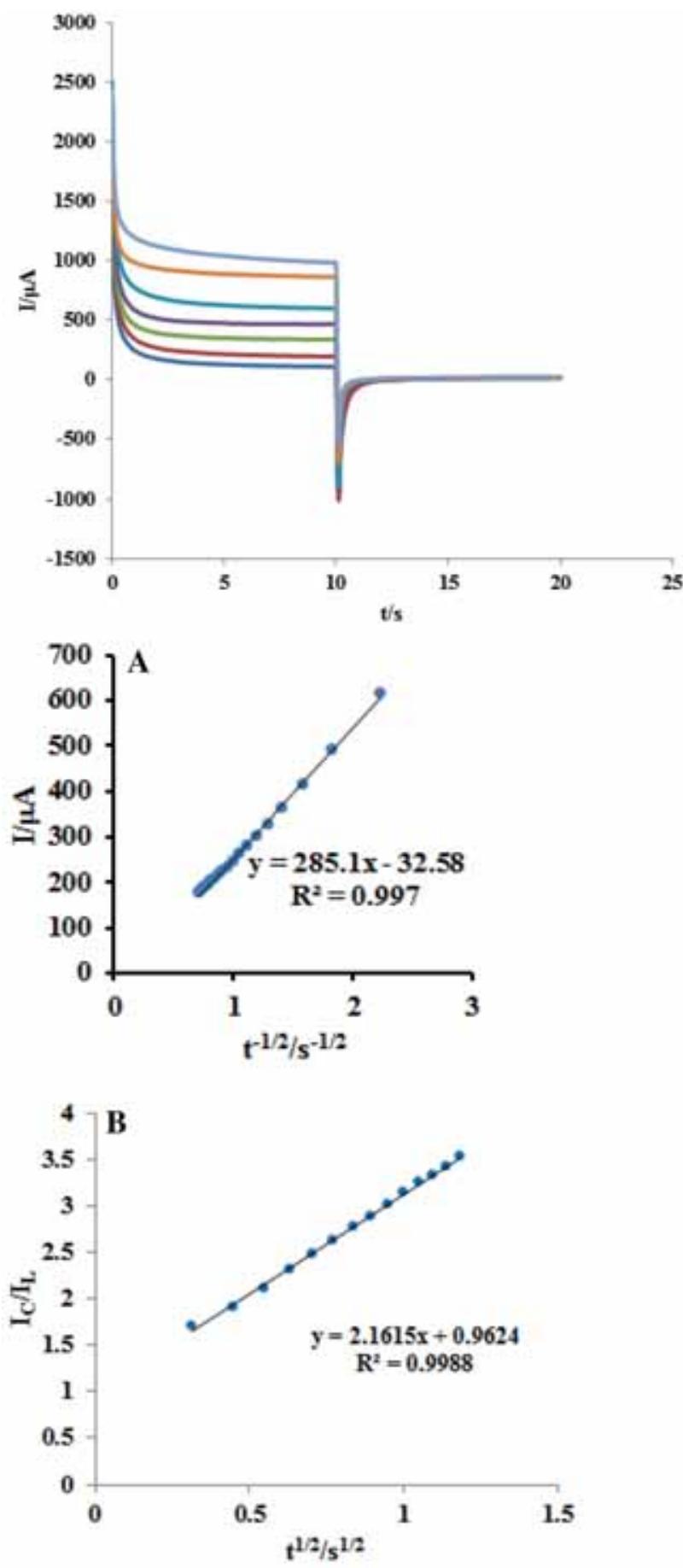

Figure 10. Chronoamperometeric curves obtained on the NiMCM-41CPE in the (a) absence and presence of (b) 0.02 , (c) 0.05 , (d) 0.08 , (e) 0.1 , (f) 0.2 and (g) 0.3 of methanol in $0.1 \mathrm{M}$ $\mathrm{NaOH}$ solution. First and second potential steps were 0.730 and $0.350 \mathrm{~V} v s . \mathrm{Ag} \mid \mathrm{AgCl}(3 \mathrm{M} \mathrm{KCl})$, respectively. Inset (A): dependence of current on $t^{-1 / 2}$, derived from the data of chronoamperogram of (a) in the main panel. Inset (B): dependence of $I_{\mathrm{C}} / I_{\mathrm{L}}$ on $t^{1 / 2}$, derived from the data of chronoamperograms.

$0.1 \mathrm{M} \mathrm{NaOH}$ is subtracted from total current density of peak $\mathrm{p}_{2}$. 
Table 3. Comparison of the current density and the oxidation potential of some nickel-modified electrodes investigated in the electrocatalytic oxidation of methanol in alkaline medium.

\begin{tabular}{lcccc}
\hline Electrode & Modifier & $j^{*}\left(\mathrm{~mA} \mathrm{~cm}^{-2}\right)$ & $E / V$ & Reference \\
\hline SBA15CPE & $\mathrm{Ni}$ & $\sim 14.2$ & $\sim 0.80 v s . \mathrm{Ag} / \mathrm{AgCl}$ & {$[25]$} \\
GC & $\mathrm{Ni}-\mathrm{Cu}$ & $\sim 46$ & $\sim 0.57 v s . \mathrm{Ag} / \mathrm{AgCl}$ & {$[54]$} \\
ZSM5CPE & $\mathrm{Ni}$ & $\sim 8.46$ & $\sim 0.72 v s . \mathrm{Ag} / \mathrm{AgCl}$ & {$[23]$} \\
GC & $\mathrm{NiMn}$ & $\sim 7.17$ & $\sim \sim 0.62 v s . \mathrm{Ag} / \mathrm{AgCl}$ & {$[55]$} \\
CPE & Poly-1,5-DAN/Ni & $\sim 1.54$ & $\sim 0.65 v s . \mathrm{Ag} / \mathrm{AgCl}$ & {$[56]$} \\
GC & $\mathrm{Ni}-\mathrm{DHS}$ & $\sim 1.25$ & $\sim 0.63 v s . \mathrm{Ag} / \mathrm{AgCl}$ & {$[57]$} \\
GC & Poly-TCPP/Ni & $\sim 1.34$ & $\sim 0.67 v s . \mathrm{SCE}$ & {$[58]$} \\
CNTPE & POT/TX-100 & 10.33 & $\sim 0.7 v s . \mathrm{Ag} / \mathrm{AgCl}$ & {$[21]$} \\
SBA16CPE & $\mathrm{Ni}$ & $\sim 13.33$ & $\sim 0.76 v s . \mathrm{Ag} / \mathrm{AgCl}$ & {$[26]$} \\
PCPE & $\mathrm{Ni}$ & $\sim 13.75$ & $\sim 0.8 v \mathrm{~s} . \mathrm{Ag} / \mathrm{AgCl}$ & {$[27]$} \\
NiMCM-41CPE & $\mathrm{Ni}$ & $\sim 11.67$ & $\sim 0.82 v s . \mathrm{Ag} / \mathrm{AgCl}$ & This work \\
\hline
\end{tabular}

DHS: N,N'-bis(2,5-dihydroxybenzylidene)-1,2-diaminobenzene, POT: poly(o-toluidine), TX: Triton X-100, CNTPE: multi-walled carbon nanotube paste electrode, DAN: 1,5-diaminonaphthalene, P: P zeolite, CPE: carbon paste electrode.

\section{Conclusions}

Natural inexpensive silica source, SCRA, provides silica source to prepare mesoporous silicate MCM-41 nanoparticles. During hydrothermal treatment of precursors, spherical mesoporous MCM-41 nanoparticles with size in the range of $20-40 \mathrm{~nm}$ are synthesized. With incorporation of $\mathrm{Ni}^{2+}$ ions into MCM-41 mixed with carbon paste, modified electrode is fabricated. The performance of electrode is considered for the electrocatalytic oxidation of methanol in alkaline solution. The obtained results show that the nonconductive MCM-41 has no role in oxidation process, and only provides a framework with large surface area for $\mathrm{Ni}^{2+}$ adsorption. The conversion of $\mathrm{Ni}(\mathrm{OH})_{2}$ to $\mathrm{NiOOH}$ during the anodic scan in alkaline solution provides the required active sites for reaction. At NiMCM-41CPE, high current densities are observed for methanol oxidation. The modified electrode can overcome sluggish kinetic process of methanol oxidation on $\mathrm{CPE}$ in alkaline solution by a catalytic $\mathrm{EC}^{\prime}$ mechanism.

\section{Acknowledgements}

We acknowledge the facilities, and the scientific and technical assistance of the University of Mazandaran for this work.

\section{References}

[1] Zhou W J, Li W Z, Song S Q, Zhou Z H, Jiang L H, Sun G Q et al 2004 J. Power Sources 131217

[2] Wang Z B, Yin G P and Shi P F 2006 Carbon 44133

[3] Hernandez-Fernandez P, Lund P B, Kallesøe Ch, Clausen H F and Christensen L H 2015 Int. J. Hydrogen Energy 40284
[4] Hosseini J, Abdolmaleki M, Pouretedal H R and Keshavarz M H 2016 J. Iranian Chem. Soc. 13815

[5] Switzer E E, Olson T S, Datye A K, Atanassov P, Hibbs M R and Cornelius C J 2009 Electrochim. Acta 54989

[6] Lin Z H, Shih Z Y, Tsai H Y and Chang H T 2011 Green Chem. 131029

[7] Raoof J B, Rashid-Nadimi S and Ojani R 2015 J. Iranian Chem. Soc. 121561

[8] Hamidi P, Ojani R, Razmi H and Razavipanah I 2015 J. Iranian Chem. Soc. 12667

[9] Telli E, Döner A and Kardas G 2013 Electrochim. Acta 107 216

[10] Abdel Rahim M A, Abdel Hameed R M and Khalil M W 2004 J. Power Sources 134160

[11] Xu C, Hu Y, Rong J, Jiany S P and Liu Y 2007 Electrochem. Commun. 92009

[12] Zabihi M S, Raoof J B, Sohrabi M R, Hosseini S R and Bamoharram F F 2016 J. Iranian Chem. Soc. 132093

[13] Zheng L and Song J 2010 J. Solid State Electrochem. 1443

[14] Golikand A N, Asgari M, Maragheh M G and Shahrokhian S 2006 J. Electroanal. Chem. $\mathbf{5 8 8} 155$

[15] Ciszewski A, Milczarek G, Lewandowska B and Krutowski K 2003 Electroanalysis $\mathbf{1 5} 518$

[16] Liu S J 2004 Electrochim. Acta 493235

[17] Jafarian M, Moghhaddam R B, Mahjani M G and Gobal F 2006 J. Appl. Electrochem. 36913

[18] Ojani R, Raoof J B and Fathi S 2009 J. Solid State Electrochem. 13927

[19] Ojani R, Raoof J B and Hosseini S R 2009 J. Solid State Electrochem. 131605

[20] Raoof J B, Karimi M A, Hosseini S R and Mangelizadeh S 2010 J. Electroanal. Chem. 63833

[21] Raoof J B, Ojani R and Hosseini S R 2011 J. Power Sources 1961855

[22] Chen Z F, Jiang Y X, Wang Y, Xu J M, Jin L Y and Sun Sh G 2005 J. Solid State Electochem. 9363

[23] Raoof J B, Azizi S N, Ojani R, Ghodrati S, Abrishamkar M and Chekin F 2011 Int. J. Hydrogen Energy 3613295

[24] Hassaninejad-Darzi S K and Rahimnejad M 2014 J. Iranian Chem. Soc. 111047 
[25] Azizi S N, Ghasemi S and Chiani E 2013 Electochim. Acta 88 463

[26] Azizi S N, Ghasemi S and Yazdani-Sheldarrei H 2013 Int. J. Hydrogen Energy 3812774

[27] Azizi S N, Ghasemi S and Amiripour F 2014 Electochim. Acta 137495

[28] Beck J S, Vartuli C, Roth W J and Kresge C T 1992 J. Am. Chem. Soc. 11410834

[29] Tangestaninejad S, Moghadam M, Mirkhani V, Mohammadpoor-Baltork I and Ghani K 2008 J. Iranian Chem. Soc. $5 \mathrm{~S} 71$

[30] Lv L, Wang K and Zhao X S 2007 J. Colloid Interf. Sci. 305 218

[31] Bruzzoniti M C, De Carlo R M, Sarzanini C, Caldarola D and Onida B 2012 Environ. Sci. Pollut. Res. Int. 194176

[32] Kalapathy U, Proctor A and Shultz J 2000 Bioresource Technol. 73252

[33] Chong A S M and Zhao X S 2003 J. Phys. Chem. B 107 12650

[34] Zhao X S, Lu G Q and Hu X 2000 Micropor. Mesopor. Mater. 4137

[35] Grisdanurak N, Chiarakorn S and Wittayakun J 2003 Korean J. Chem. Eng. 20950

[36] Bessel C A and Rolison D R 1997 J. Phys. Chem. 101 1148

[37] Fleischmann M, Korinek K and Pletcher D 1971 J. Electroanal. Chem. 3139

[38] Allen J R, Florido A, Young S D, Daunert S and Bachas L G 1995 Electroanalysis 7710

[39] Laviron E 1979 J. Electroanal. Chem. 10119

[40] Luo H, Shi Z, Li N, Gu Z and Zhuang Q 2001 Anal. Chem. 73 915

[41] Sattarahmady N, Heli H and Faramarzi F 2010 Talanta 82 1126
[42] Taraszewska J and Roslonek G 1994 J. Electroanal. Chem. 364 209

[43] Zheng L and Song J F 2010 J. Solid State Electrochem. 14 43

[44] Danaee I, Jafarian M, Forouzandeh F, Gobal F and Mahjani M G 2009 Int. J. Hydrogen Energy 34895

[45] Subbaiah T, Mallick S C, Mishra K G, Sanjay K and Das R P 2002 J. Power Sources 112562

[46] Robertson P M 1980 J. Electroanal. Chem. 11197

[47] Nozad Golikand A, Shahrokhian S, Asgari M, Ghannadi Maragheh M, Irannejad L and Khanchi A 2005 J. Power Sources 14421

[48] Spinner N and Mustain W 2011 Electrochim. Acta 56 5656

[49] El-Shafei A A 1999 J. Electroanal. Chem. 47189

[50] Singh R N, Sharma T, Singh A, Anindita, Mishra D and Tiwari S K 2008 Electrochim. Acta $\mathbf{5 3} 2322$

[51] Greef R, Peat R, Pletcher L M and Robison J 1985 Instrumental methods in electrochemistry (Chicherster: Ellis Horwood) p 185

[52] Gosser D K (ed) 1994 Cyclic voltammetry simulation and analysis of reaction mechanism (NewYork: $\mathrm{VCH}$ )

[53] Galus Z 1976 Fundamentals of electrochemical analysis (New York: Ellis Horwood) p 431

[54] Danaee I, Jafarian M, Forouzandeh F, Gobal F and Mahjani M G 2008 Int. J. Hydrogen Energy 334367

[55] Danaee I, Jafarian M, Mirzapoor A, Gobal F and Mahjani M G 2010 Electrochim. Acta 552093

[56] Ojani R, Raoof J B and Hosseini S R 2008 Electrochim. Acta 532402

[57] Parra M-R, García T, Lorenzo E and Pariente F 2008 Sens. Actuat. B 130730

[58] Jafarian M, Haghighatbin M A, Gobal F, Mahjani M G and Rayati S 2011 J. Electroanal. Chem. 66314 